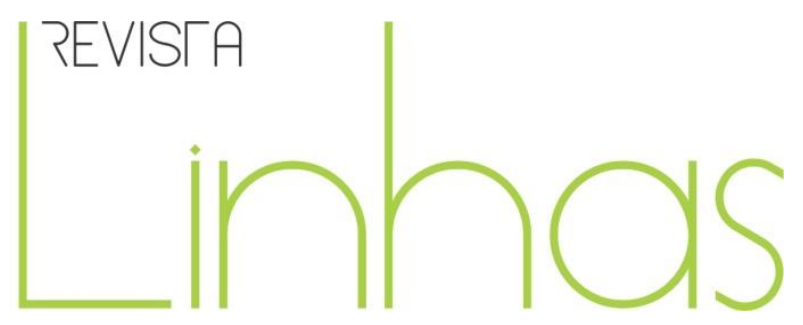

\title{
Revisitar a formação de educadores/as de infância através da Revista Aprender (1987-2015)
}

\begin{abstract}
Resumo
Neste artigo propomos discutir, de um modo geral, a Educação de Infância/ Educação Pré-Escolar portuguesa nos últimos trinta anos (idades compreendidas entre os 3 anos e a entrada no $1^{\circ}$ ano de escolaridade) a partir de uma realidade institucional específica. A importância da Educação de Infância é cada vez mais salientada por vários autores (CARDONA, 1997; CASTANHEIRA, 2011; MARCHÃO, 2012). Neste sentido, quisemos compreender que tipo de pensamento pedagógico se foi produzindo sobre a Educação de Infância no âmbito da Escola Superior de Educação e Ciências Sociais do Instituto Politécnico de Portalegre (Portugal) desde a década de 80 da centúria passada. Para o efeito, socorremo-nos de um periódico publicado pela instituição escolar - a revista APRENDER entre 1987 e 2015 (último número publicado). Optamos por uma análise mista (qualitativa e quantitativa) e crítica que permitiu discutir e encontrar tendências relacionadas com este campo de saberes direcionado para as crianças mais novas. Defendemos que, apesar de esta revista ter sido publicada numa instituição formadora de educadores e professores, não se verifica quantitativamente uma relação de importância direta com a produção do pensamento ali publicado. Por outro lado, o conjunto de ideias que circularam corresponde ao pensamento pedagógico produzido em Portugal com influências diversas, nomeadamente do Estado.
\end{abstract}

Palavras-chave: Educação de Infância. Imprensa de Educação e Ensino. Professores de Educação Pré-Escolar. Formação. Educação de Crianças - Portugal.

\author{
Helder Henriques \\ Instituto Politécnico de \\ Portalegre \\ Ceis20 - Universidade de \\ Coimbra - Portugal \\ helderhenriques@esep.pt \\ Amélia Marchão \\ Instituto Politécnico de \\ Portalegre/ C3l - Portugal \\ ameliamarchao@esep.pt
}

\footnotetext{
Para citar este artigo:

HENRIQUES, Helder; MARCHÃO, Amélia. Revisitar a formação de educadores/as de infância através da Revista Aprender (1987-2015). Revista Linhas. Florianópolis, v. 18, n. 38, p. 160-182, set./dez. 2017.
}

DOI: $10.5965 / 1984723818382017160$

http://dx.doi.org/10.5965/1984723818382017160

${ }^{11}$ Optou-se por manter a grafia da língua nativa (Língua Portuguesa - Portugal). 


\title{
Revisiting the training of childhood educators through the Magazine Aprender (1987-2015)
}

\begin{abstract}
In this article we propose to discuss, in a general way, the Portuguese Childhood Education in the last thirty years (ages between 3 years old and entering the first year of schooling) from a specific institutional reality. The importance of Childhood Education is increasingly emphasized by several authors (CARDONA, 1997; CASTANHEIRA, 2011; MARCHÃO, 2012). In this way, we wanted to understand what kind of pedagogical thinking has been produced about Childhood Education within the framework of the Higher School of Education and Social Sciences of the Polytechnic Institute of Portalegre (Portugal) since the 8os of the last century. For this purpose, we have used a newspaper published by the school institution - the magazine APRENDER - between 1987 and 2015 (last issue). We opted for a mixed (qualitative and quantitative) and critical analysis that allowed us to discuss and find trends related to this field of knowledge directed to younger children. We argue that although this journal has been published in an institution that trains educators and teachers, it is not quantitatively a relation of direct importance to the production of thought published there. On the other hand, the set of ideas that circulated correspond to the pedagogical thought produced in Portugal with different influences, namely the action of the State. ${ }^{2}$
\end{abstract}

Keywords: Childhood Education. Education and Teaching Press. Education of Children - Portugal. Teachers of Pre-School Education - Training.

\footnotetext{
${ }^{2}$ Tradução de Vanda Ribeiro, Instituto Politécnico de Portalegre.
} 


\section{Introdução}

O texto que nos propomos realizar encontra-se ancorado na necessidade de conhecer, compreender e analisar o campo de produção do pensamento pedagógico relacionado com a Educação de Infância em Portugal. Esta inquietação prende-se com a nossa atividade profissional enquanto formadores de professores/as e de educadores/as na Escola Superior de Educação e Ciências Sociais do Instituto Politécnico de Portalegre (ESECS - IPP) - Portugal.

Assim, colocamos a seguinte questão orientadora: que evidências pedagógicas podemos encontrar no âmbito das escolas de formação de professores e/ou educadores no campo da educação de infância em Portugal? Para dar resposta a este problema focarnos-emos na realidade da ESECS - IPP, num arco temporal que se desenvolve entre meados dos anos 80 , do século $\mathrm{XX}$, até ao presente, e, ainda, no estudo do periódico institucional: a Revista Aprender (1987-2015), publicada pela ESECS-IPP até à atualidade.

Para o efeito, mobilizamos um conjunto de autores que se têm preocupado com a formação de educadores/as e com a História da Educação de Infância em Portugal (GOMES, 1986; BAIRRÃO \& VASCONCELOS, 1997; CARDONA, 1997; MAGALHÃES, 1997; CASTANHEIRA, 2011; MARCHÃO, 2012; HENRIQUES \& MARCHÃO, 2014; MARCHÃO \& HENRIQUES, 2015, entre outros). O corpus documental em análise é constituído, além da legislação, por fontes de arquivo da ESECS-IPP e pela imprensa pedagógica institucional, em particular a Revista Aprender.

A imprensa pedagógica surge neste trabalho como uma fonte relevante para a compreensão das problemáticas educativas. É neste sentido que realçamos as palavras de Catani (2013, p. 115) quando afirma, expondo o caso brasileiro, que no âmbito da investigação em história da educação “o recurso aos materiais da imprensa periódica pedagógica para a compreensão das concepções, práticas, atuações, métodos e outras referências ao ensino e à vida escolar (...)" são elementos centrais à compreensão das várias áreas de trabalho relacionadas com o passado educativo. Neste sentido, também Hernandez Diaz (2015), exemplificando com o caso de Espanha (Castela e Leão), afirma o seguinte: 
La prensa pedagógica, desde su própria identidade, se convierte en un objecto historiográfico especifico, com un valor añadido, en la medida que se erige en um canal informativo de los problemas educativos del tiempo histórico en que desempeñ su atividade. Por otra parte, la prensa pedagógica representa una forma posible de aproximación al conocimiento del sistema educativo (en este caso de españa), diferente a las clásicas formas de conocimiento histórico, porque la prensa pedagógica incluye el mismo tiempo una lectura transversal del problema educativo que se aborda, que combina la dimension normativa, com la denuncia, com la difusión de nuevas ideas y pautas pedagógicas. (p. 10)

De acordo com as considerações que o autor tece, acerca da importância da imprensa pedagógica e das suas potencialidades na construção de novos entendimentos no âmbito da história da educação, procuramos evidenciar a dimensão da produção do pensamento pedagógico associada a uma instituição de formação professores e de educadores.

No que respeita à abordagem metodológica, optamos por uma abordagem de natureza mista (qualitativa e quantitativa) que permite a identificação e análise de momentos específicos da formação de educadores/as e da produção de saber relacionado com a Educação de Infância emergente, sobretudo, a partir da revista em análise.

Em compêndio, tentamos compreender e interpretar, à luz do contexto institucional, cuja matriz inicial assentava na formação de educadores/as e professores/as, a importância atribuída à Educação de Infância e os princípios pedagógicos desenvolvidos em Portugal, através de uma realidade institucional específica.

\section{A Educação de Infância em Portugal: sumário de um trajeto}

Ao longo da modernidade educativa o interesse pela infância foi aumentando dado que esta etapa da vida passou a ser considerada um elemento fundamental no processo de consolidação do Estado-Nação. Gradualmente, a infância tornou-se o epicentro de uma teia discursiva e normativa que a rodeou, permitindo a cientistas, políticos ou outros especialistas dirigir à infância um projeto biopsicossocial e político (HENRIQUES; VILHENA, 2015). 
A Escola fez parte deste projeto político onde se procurou moldar as crianças mais novas de acordo com princípios sociomorais adequados e enquadrados com os diversos momentos políticos. É neste contexto que Almeida (2009), seguindo de perto Perrenoud (1996), fala num processo de modelação da criança no que o adulto, ou estruturas por si geridas, pretendia que ela se transformasse.

Isto significa que as instituições escolares podem ser entendidas como dispositivos de poder capazes de assumir uma dupla condição: por um lado, favorecer a manutenção da ordem social; e, por outro lado, conduzir a conduta dos indivíduos através do estudo das suas condições físicas e psicológicas. A este propósito, Foucault (2006) refere-se à importância da qualidade das populações. Quanto maior, mais preciso e antecipado for o conhecimento das populações melhor se podem transformar e adequar aos princípios propostos. Como afirmam Henriques \& Vilhena (2015, p. 65), o principal objetivo era o de “construir uma sociedade governável, de acordo com determinadas racionalidades produtoras de ordem social, a partir de cada um dos indivíduos."

É no interior deste contexto da modernidade que surgem vários enquadramentos institucionais, entre eles os jardins de infância, com duplo objetivo: por um lado, a perspetiva assistencialista (o cuidar); e, por outro lado, a perspetiva educativa (o educar). Ambas as perspetivas decorrem do processo de industrialização da Europa e da necessidade de cuidar e educar os filhos mais novos das famílias mais pobres e do operariado (FERNANDES, 2006, p. 180). Ao longo do século XX, os jardins de infância construíram-se em torno destas duas perspetivas.

Em Portugal, o primeiro jardim de infância foi inaugurado pela Câmara Municipal de Lisboa, em 1882, no Jardim da Estrela, inspirado nas pedagogias Fröebelianas. Foi, porém, com a $10^{a}$ República Portuguesa que se criou oficialmente a educação infantil (1911), para crianças entre os 4 e os 7 anos de idade (NÓVOA, 1994). Mais tarde, com o regime político ditatorial, liderado por António de Oliveira Salazar, a infância passou a ser entendida como uma função natural do sexo feminino, em particular das mães a quem o regime político reservava um lugar na esfera privada. Este novo entendimento provocou, em 1937, a extinção do ensino infantil público, anteriormente criado (VASCONCELOS, 2005). Apenas com a Revolução de 25 de Abril de 1974, assistimos em Portugal à 
emergência de espaços preparados para cuidar e educar as crianças mais novas e a um processo de valorização da educação de infância que decorre até ao presente.

Ao longo do atual regime democrático evidenciaram-se dois momentos principais relacionados com a educação das crianças mais novas. O primeiro momento decorre da Revolução dos Cravos, em 1974, até à publicação da Lei-Quadro da Educação Pré-Escolar, em 1997. O segundo momento, inicia-se com a publicação do anterior diploma legal e prolonga-se até aos dias de hoje. No decorrer destes momentos assinalados devemos, no caso do primeiro, salientar dois diplomas legais: o Estatuto dos Jardins de Infância da rede pública (1979) e a publicação da Lei de Bases do Sistema Educativo (LBSE) (1986).

Assim, face à necessidade emergente da Revolução dos Cravos de se construir uma nova sociedade, democrática, plural, livre e mais justa, a Constituição da República Portuguesa, promulgada em 1976, previa já uma aposta na criação de um sistema público de educação pré-escolar (art. 74). Esta ideia foi ganhando relevância e passou a fazer parte de uma nova teia política discursiva. Contudo, na prática a regulamentação da matéria sobre a educação pré-escolar aconteceu em 1979, quando foi publicado o Estatuto dos Jardins de Infância da rede pública (Decreto-Lei n. ${ }^{\circ}$ 542/79). Este documento legal assumia a necessidade dos profissionais de educação de infância possuírem formação adequada, devendo "estar habilitados com a aprovação num curso oficial de educadores de infância, com a duração não inferior a três anos, neles incluído o estágio de prática pedagógica" (art. 45). Este foi um primeiro passo relevante no processo de valorização profissional da educação de infância em Portugal.

Além desta dimensão, verifica-se uma preocupação em definir concretamente o que se pretendia para a educação pré-escolar. O Estado Português assumia esta etapa da vida correspondente à educação pré-escolar como um momento em que era necessário garantir as condições para um desenvolvimento global da criança, assim como a sua missão também passava pelo combate às assimetrias sociais no acesso ao sistema escolar, bem como a necessidade de construir cidadãos úteis e vocacionados para o “progresso espiritual, moral, cultural, social e económico da comunidade” (art. $1^{\circ}$ ).

De forma a responder a estes princípios gerais, atribuídos à educação pré-escolar, o diploma propunha também os principais objetivos que deveriam ser cumpridos no processo formativo: contribuir para a estabilidade e segurança afetiva da criança; 
favorecer capacidades de expressão, comunicação e criação; despertar a curiosidade; promover a autonomia da criança; desenvolver hábitos de higiene e de defesa da saúde; despistar problemas de saúde físicos ou de natureza psicológica; estimular as atividades de grupo e, por fim, assegurar a participação das famílias no processo educativo (Art. $2^{\circ}$ ). Este conjunto de objetivos constitui, em grande medida, os principais elementos norteadores da ação dos profissionais da educação de infância. Na verdade, este diploma legal veio influenciar de modo efetivo a construção dos fundamentos da educação préescolar na Lei de Bases do Sistema Educativo, uma vez que a sua manutenção, em 1986, sugere a importância e adequação dos mesmos à realidade que se pretendia construir. É inegável que a educação pré-escolar encontra na Lei de Bases do Sistema Educativo um espaço de manobra que nunca tinha conseguido anteriormente.

A LBSE define que a EPE se destina a crianças entre os três anos e a idade de ingresso no ensino básico (Lei n. ${ }^{\circ}$ 46/86). Esta lei entende a EPE como complementar e/ou supletiva da ação educativa da família, com a qual deve estabelecer uma articulação estreita “... que se exprime pela garantia de uma permanente ação formativa orientada para favorecer o desenvolvimento global da personalidade, o progresso social e a democratização da sociedade." (Diário da República, I Série, n² 237 de 14 de outubro de 1986).

Do ponto de vista dos objetivos definidos para a educação pré-escolar, correspondem em grande medida, aos princípios já enunciados na legislação de 1979. Não obstante, sugerem uma ação mais profunda, do ponto de vista educativo, no desenvolvimento das capacidades de cada criança de modo a permitir a construção de cidadãos plenos, com uma formação global e equilibrada (CARDONA, 1997, p. 97).

A afirmação e consolidação destes princípios levam-nos ao segundo momento que evidenciamos anteriormente com a publicação da Lei-Quadro da Educação Pré-Escolar (Lei n. ${ }^{\circ}$ 5/97) e a publicação das Orientações Curriculares para a Educação de Infância (1. ${ }^{\text {a }}$ edição em 1997, 2. ${ }^{a}$ edição/revista em 2016). Estes dois documentos, em articulação com o Plano de Expansão e Desenvolvimento da Educação Pré-Escolar (Decreto-Lei n. ${ }^{\circ}$ 147/97), constituem, em nosso entender, o momento de maior relevância no que respeita à afirmação da educação de infância em Portugal. 
A LQEPE (Lei n. ${ }^{\circ}$ 5/97) “consagra o ordenamento jurídico da educação pré-escolar” na sequência daquilo que a LBSE (1986) já propusera uma década antes. Manteve os princípios gerais que continuaram dirigidos às crianças entre os 3 anos e a idade de admissão no ensino básico. Porém, introduziu um elemento discursivo novo que caracteriza a EPE como "a primeira etapa da educação básica no processo de educação ao longo da vida" (Art. 1. ${ }^{\circ}$ ). Constituem objetivos da educação pré-escolar, de acordo com a LQEPE (1997), entre outros:

1. Promover o desenvolvimento pessoal e social da criança com base em experiências de vida democrática numa perspetiva de educação para a cidadania;

2. Fomentar a inserção da criança em grupos sociais diversos, no respeito pela pluralidade das culturas, favorecendo uma progressiva consciência do seu papel como membro da sociedade;

3. Contribuir para a igualdade de oportunidades no acesso à escola e para o sucesso da aprendizagem;

4. Estimular o desenvolvimento global de cada criança, no respeito pelas suas características individuais, incutindo comportamentos que favoreçam aprendizagens significativas e diversificadas;

5. Desenvolver a expressão e a comunicação através da utilização de linguagens múltiplas como meios de relação, de informação, de sensibilização estética e de compreensão do mundo;

6. Despertar a curiosidade e o pensamento crítico;

7. Proporcionar a cada criança condições de bem-estar e de segurança, designadamente no âmbito da saúde individual e coletiva;

8. Proceder à despistagem de inadaptações, deficiências e precocidades, promovendo a melhor orientação e encaminhamento da criança;

9. Incentivar a participação das famílias no processo educativo e estabelecer relações de efetiva colaboração com a comunidade. (Lei $\mathrm{n}^{\circ}$ 5/97, Art. $\left.10 .^{\circ}\right)$

O conjunto de princípios enunciados ancora-se na LBSE (1986) onde se valoriza a criança e o seu desenvolvimento global. Assume-se também a necessidade de preparar a criança para os novos desafios da sociedade com destaque para as problemáticas diversas de educação para a cidadania, em particular as questões da igualdade de género e/ou de oportunidades no acesso à escola, o respeito pela diversidade, permitindo a construção de uma consciência cidadã. Na mesma linha de ideias, a LQEPE (1997) reconhece a ação complementar do jardim de infância face à centralidade que a família deverá ter no processo educativo das crianças. 
A afirmação da criança-cidadã continua com a publicação da primeira (1997) e segunda (2016) versões das Orientações Curriculares para a Educação Pré-Escolar (OCEPE). As OCEPE (2016) constituem elementos orientadores para a prática da educação de infância. Sumariamente, as OCEPE corroboram as lógicas inscritas na LBSE (1997) e na LQEPE (1997). Definem, ainda, a tutela pedagógica única dos jardins de infância criando um conjunto de mecanismos capazes de potenciar a profissão do educador de infância e melhorar, gradualmente, a sua imagem social.

Centramos a publicação das OCEPE no interior de duas dimensões: por um lado, é afirmada a importância da qualidade dos contextos educativos atendendo às problemáticas atuais como as questões das assimetrias sociais, equidade, diferença, ou igualdade de oportunidades entre homens e mulheres. Por outro lado, do ponto de vista pedagógico, constituem um avanço na perspetiva do direcionamento dos objetivos da Educação Pré-Escolar para o desenvolvimento e aprendizagem da criança. Neste contexto, o brincar surge como elemento âncora do trabalho desenvolvido nos contextos educativos.

Hoje é reconhecida a necessidade de universalização da EPE no sistema educativo português. Possuímos uma rede de jardins de infância (públicos, particulares/de solidariedade social ou privados) que serve os meios urbanos e os meios rurais estando criadas as condições para colocar todas as crianças em contextos educativos desde, pelo menos, os três anos de idade. Atualmente, todos devem ser envolvidos na gestão e construção do currículo em educação de infância. Esta perspetiva global e de formação integral fez o seu caminho através dos vários modelos pedagógicos implementados em Portugal (High Scope; Reggio Emilia; Escola Moderna, outros) na segunda metade do século XX, mas também através da legislação e das OCEPE publicadas pelo Estado Português. 


\section{Pensar a formação de educadores: o caso da Escola Superior de Educação e Ciências Sociais do Instituto Politécnico de Portalegre}

A formação de professores e educadores de infância constitui em qualquer sistema educativo uma preocupação permanente. Depois da Revolução de Abril de 1974, esta preocupação materializou-se com a resposta oferecida pelo Estado português: a fundação das Escolas Superiores de Educação (ESE). Estas instituições vieram oferecer uma oportunidade de dignificar, por via da atribuição de graus académicos, a profissão de educador de infância. Assistimos, ao longo dos anos 80 do século XX, à abertura de várias dessas instituições nas capitais de distrito de Portugal.

Assumimos, no contexto deste artigo, o caso da Escola Superior de Educação de Portalegre (hoje designada de Escola Superior de Educação e Ciências Sociais do Instituto Politécnico de Portalegre). A Escola Superior de Educação de Portalegre foi a primeira instituição de ensino superior a ser fundada no alto Alentejo (Portugal). Ocupou um antigo Palácio - Achaiolli - (anteriormente ocupado pelo Liceu de Portalegre) e iniciou as atividades no ano de 1985. Foram criados cursos de formação inicial e de formação em serviço (Esep, 1990, p. 7).

Como referem Henriques, Marchão \& Mourato (2015) "a abertura destas instituições constituiu uma oportunidade para muitas pessoas que frequentaram o ensino superior politécnico dada a importância da sua proximidade" (p. 186). Porém, além dos cursos de formação iniciados, onde se encontrava, entre outros, o de educadores de infância, foi também criado um instrumento pedagógico da maior importância para professores, alunos e comunidade em geral: a revista Aprender (1987). No primeiro editorial do periódico podemos ler o seguinte:

A utopia de "Aprender a Ser" é a nosso ver a orientação "realista" que permite perspetctivar os grandes eixos da mudança em educação, em torno de três grandes tendências que (em oposição ao mito da GRANDE REFORMA), a partir de experiências parcelares, se vão desenhando:

- a educação permanente, como principio organizador de todo o sistema educativo conduzindo à inversão da importância relativa da educação escolar e extra-escolar;

- a inovação permanente como estratégia de transformação global do sistema, apostando na criatividade a participação dos diferentes actores sociais e na busca sistemática de novas soluções, num quadro plural que se contrapõe a modelos uniformizados; 
- redimensionamento à escala comunitária das instituições educativas (escolares e não escolares) na polivalência e integração das suas funções sociais (CANÁRIO, 1987, n. ${ }^{\circ}$ 1, p. 1)

Esta revista, ainda em publicação, serviu/serve de elemento reflexivo sobre os mais diversos assuntos relacionados com a formação de professores e de educadores e assume a ideia da mudança, numa perspetiva adaptada às circunstâncias locais, como desígnio maior. A publicação reflete a ambição de transformar o ensino superior num elemento promotor de desenvolvimento económico e social (CANÁRIO, n. ${ }^{1}$, jan. 1987). De acordo com o primeiro diretor da revista (Professor doutor Rui Canário) a revista Aprender deveria contribuir para o "debate de ideias, (...) troca de experiências, (...) incentivo à investigação" (n. 1 , p. 2). Os textos são, na sua maioria, assinados pelos professores da Escola. Todavia, há um conjunto de convidados presentes na revista onde se destacam os nomes de António Nóvoa, Teresa Vasconcelos ou de Maria do Céu Roldão, entre muitos outros.

A revista pode caraterizar-se em função de três grandes tipologias: os textos relacionados com a formação de professores e de educadores; textos direcionados para as políticas educativas, métodos de ensino e administração escolar; e, por fim, os textos que evidenciam uma relação de proximidade da instituição formadora de professores e de educadores e a comunidade regional e local. Mas recuperemos, no essencial, a nossa questão de partida: que ideais pedagógicos circulavam na revista Aprender, relacionados com a educação de infância em Portugal, direcionados para a formação dos novos profissionais?

\subsection{Produção e influências do pensamento pedagógico: o caso da educação de infância através da revista Aprender}

A análise realizada permitiu identificar 485 textos publicados entre 1987 e 2015. Do conjunto dos textos identificados, apenas 48 dizem respeito ao campo específico da Educação de Infância (cerca de 10\%). Este primeiro indicador revela alguma ausência de investimento numa área de formação que foi procurada por um conjunto significativo de estudantes, até aos dias de hoje (HENRIQUES, MARCHÃO, MOURATO, 2015). 
As principais temáticas relacionadas com a educação de infância que identificamos, podem agrupar-se em três grandes conjuntos: pedagogia (s) para a infância; formação de educadores de infância e experiências pedagógicas.

Relativamente ao primeiro conjunto, identificamos 16 textos, com especial destaque para três aspetos: a aplicabilidade de saberes diversos (geografia, literatura, matemática, etc..) em contexto de educação pré-escolar; modelos pedagógicos para a educação de infância; e, as preocupações com o processo de transição das crianças para o ensino primário ( $1 .^{\circ}$ ciclo do ensino básico). A análise da revista permitiu compreender que existiu, sobretudo numa fase inicial, uma necessidade de colocar em evidência as vantagens da aplicação de um conjunto de saberes (matemática, geografia, história, entre outros) no contexto educativo do jardim de infância. A este propósito Maria de Lurdes Serrazina (1988), à época professora adjunta da Escola Superior de Educação de Lisboa, afirmava a importância da valorização do conhecimento matemático que as crianças já traziam, fruto das mais diversas experiências que já tinham vivido. Assim, afirmava:

(...) é preciso não esquecer que as crianças são indivíduos activos que vão construindo o seu conhecimento na interacção com o mundo físico, os materiais e as outras crianças. Por isso, a aprendizagem da matemática deve constituir um processo activo e ser feita num ambiente em que as crianças sejam encorajadas a explorar, testar, discutir e aplicar ideias (SERRAZINA, 1988, p. 23)

A valorização do meio que rodeia a criança, enquanto elemento integrante do processo de ensino e de aprendizagem, pode constituir um mecanismo fundamental na construção de uma atitude positiva face à aprendizagem da matemática. Esta linha de pensamento pode ser encontrada quando analisamos outros textos publicados na Aprender relacionados com outras áreas do saber.

Os modelos pedagógicos são outro assunto com destaque neste primeiro conjunto que evidenciamos ao longo da publicação do periódico. Exemplo desta discussão é o artigo assinado por Teresa Vasconcelos (julho de 1990), na edição n. ${ }^{\circ}$ 11, da Aprender. A autora desenvolve um estudo direcionado para os educadores, na sequência de algumas afirmações que apontavam aos educadores portugueses a inexistência de um modelo pedagógico claro que permitisse uma intervenção devidamente fundamentada. 
Vasconcelos assume que naquela época havia uma necessidade de apostar na formação inicial e contínua dos educadores para "eventualmente ajudá-los a fazer um percurso de clarificação e análise crítica dos seus modelos ou quadros de referências" (p. 44). Afirma, contudo, que este trabalho implica a criação de condições necessárias ao desenvolvimento da sua prática, nomeadamente de espaços e tempos para "com outros educadores, entrarem num processo de investigação da sua prática” (p. 44). No essencial, Vasconcelos (julho de 1990) refere a importância de ligar as políticas educativas com as realidades locais, assim como aponta a importância da difusão da educação préescolar e de valorização da atividade profissional. Este contexto identificado pela autora, começou a ganhar novos contornos no começo da década de 90 do século XX, todavia apenas no final do decénio foi publicada a Lei-quadro de Educação Pré-Escolar, assim como as primeiras Orientações Curriculares para a Educação Pré-escolar (1997).

Outro aspeto da maior importância prende-se com a relevância atribuída no âmbito da Aprender ao processo de transição das crianças entre a Educação Pré-Escolar e o 1. ${ }^{\circ}$ Ciclo do Ensino Básico. Em 2002, Amélia Marchão coordenou um número especial sobre esta matéria. No editorial deste número, a autora afirmava a necessidade de construir canais de comunicação entre a "primeira etapa da educação básica" (EPE) e o início da escolaridade obrigatória. Para o efeito, constatava que era necessário preparar a criança para os momentos de transição:

\footnotetext{
Mas, mais do que isso, estar atentos aos percursos vividos para agir em função dos significados que a criança constrói e que lhe permitem aprender sem repetições e sem rupturas, assumindo-se e fazendo-se reconhecer como uma das peças fundamentais na gestão do currículo e da escola na sua globalidade (MARCHÃO, 2002, p. 3)
}

Neste número especial participaram autores diversos que assumiram a centralidade da preocupação referida. Falamos de Gabriela Portugal, Maria Isabel Lopes da Silva (autora das OCEPE de 1997 e coordenadora da edição de 2016), Maria Graciete Monge, Amélia de Jesus Marchão, Maria João Cardona, Luísa Álvares Pereira ou Maria Emília Monteiro Nabuco.

Sobre este assunto Silva (2002) afirmava que havia necessidade das educadoras e dos professores aprofundarem o conhecimento sobre as realidades de ambos. Tornava- 
se, segundo a autora, fundamental um trabalho de articulação entre a educação préescolar e o $10^{\circ}$ ciclo do ensino básico, com vantagens para a criança. Revelava a necessidade de investir mais em formação contínua de modo a conhecer a "abundante investigação sobre a aprendizagem" (p. 25).

Monge (2002) refere a necessidade de se conhecer e acompanhar a criança no processo de vivência da transição, assim como realça o papel dos pais, e das próprias crianças, neste processo. Desta forma, defende o seguinte:

Uma palavra final impõe-se aos profissionais. Se num processo formativo há que assegurar uma linha de continuidade educativa que elimine rupturas nos períodos de transição e possibilite a natural sequência e complexidade das aprendizagens, exige-se também a reflexão sobre as dimensões que a continuidade engloba, o poder de decisão e construção curricular de que a escola dispõe, as atitudes e práticas profissionais facilitadoras da sua concretização, o conhecimento mútuo e o intercâmbio indispensáveis.

As opiniões das crianças, as opiniões dos pais podem ser um elemento importante de reflexão sobre a própria actuação dos docentes num jardim de infância ou numa escola de $1^{\circ}$ ciclo. Talvez este seja, de facto, o ponto inicial da continuidade que se pretende (MONGE, 2002, p. 31)

Provavelmente, a definição identitária da educação pré-escolar, onde se aprende a brincar, e o modelo escolarizante do $10^{\circ}$ ciclo do ensino básico constituíram os aspetos que mais dificultaram a transição das crianças entre estes contextos. Parece óbvia a necessidade de não criar uma linha de tensão na vida da criança nestes processos que devem ser de harmonia, de modo a valorizar as aprendizagens e o sujeito criança. Para o efeito, a comunicação e a pedagogia da escuta da própria criança podem resultar e facilitar toda esta dinâmica desenvolvida na Aprender.

O segundo conjunto que se evidenciou no âmbito da análise efetuada prende-se com aspetos direcionados para a formação de educadores de infância. Neste âmbito identificamos 11 textos que se dividem em dois grupos: por um lado, modelos de formação inicial no âmbito das escolas superiores de educação; por outro lado, reflexões sobre o futuro da formação de educadores de infância. 
Natércio Afonso (1987), logo no número inicial do periódico, afirmava a necessidade das Escolas Superiores de Educação se diferenciarem dos modelos existentes até aí no âmbito da formação de professores. Propunha, então, a afirmação das ESE de acordo com cinco pilares: uma formação integrada; uma formação de nível superior; uma formação para a regionalização; uma formação para a qualidade; uma formação permanente. O caminho destas novas instituições de formação de professores e educadores deveria pautar-se por estes eixos porque respondia a um novo modelo social que pretendia "ultrapassar a dicotomia entre dois tipos de formação, social e profissionalmente discriminatória" (AFONSO, 1987, p. 9) através de um sistema vertical de formação numa mesma instituição, desde os cursos de educadores de infância até aos anos subsequentes de escolaridade.

No mesmo sentido, Marchão (1995) refere a importância das Escolas Superiores de Educação no contexto da formação inicial e continua. Em 1995, a autora referia que, no caso concreto da formação de educadores de infância “... deve guiar-se por uma lógica de acção que permita formar educadores com capacidade de participação, de intervenção e de reflexão da e na educação". E acrescenta mesmo que "a uma formação meramente escolarizante deverá contrapor-se uma lógica de acção em que a formação surja no contexto do jardim de infância (... )" (MARCHÃO, 1995, p. 98). Com um pensamento claro e definido, sobre o rumo que a Educação de infância deveria tomar, Marchão (1995) apontava já para a necessidade da qualidade da formação e da especificidade que as ESE deveriam oferecer no âmbito da formação de educadores, nomeadamente através da valorização entre a teoria e a prática em contexto educativo.

O segundo aspeto que ao longo da análise do periódico se foi tornando evidente prende-se com as áreas de trabalho futuro no âmbito da educação de infância. Também neste caso Marchão (1998) afirma que a aposta deveria passar pela creche. Este caminho permitiria construir contextos educativos mais ricos, proporcionar mais experiências de aprendizagem e torná-los qualitativamente mais eficazes no processo de desenvolvimento da criança. Para o efeito, esta aposta deveria iniciar-se logo no momento da estruturação dos cursos de formação de educadores de infância que, segundo a autora, deveria basear-se numa "perspetiva construtivista e reflexiva" colocada em confronto com o "mundo real e profissional" que aguarda o educador. 
Este constitui o caminho para uma verdadeira definição identitária destes profissionais. No fundo, a autora consegue antecipar aquilo que ainda hoje é uma problemática e discussão atual. Por um lado a questão do alargamento da educação préescolar para as crianças com idade inferior a 3 anos; e, por outro lado, a ideia da necessidade da articulação entre o que se faz nas instituições de formação e aquilo que acontece nos jardins de infância, em particular no âmbito da formação para/em creche.

A Escola Superior de Educação de Portalegre parece ter incorporado as ideias desta professora. Ao longo dos números seguintes são várias as referências a aspetos relacionados com os contextos educativos em jardim de infância, a dimensão qualitativa desses contextos, as problemáticas em torno das crianças, entre muitas outras considerações.

Neste sentido, o terceiro conjunto de elementos prende-se com a dimensão prática da formação de educadores de infância: o contexto específico da aprendizagem em jardim de infância. Neste ponto encontramos vários relatos (14) relacionados com experiências e projetos pedagógicos que foram desenvolvidos no âmbito de estágios em contexto educativo. É também de assinalar, nos últimos números da publicação, a emergência de uma linha de trabalho associada às problemáticas da igualdade de género e cidadania.

Em 1987, a Aprender publicou um número com destaque para as experiências pedagógicas enquanto oportunidades significativas de aprendizagem no contexto educativo em análise. Nesse número são dados vários exemplos de atividades planificadas e aplicadas pelos alunos do curso de educação de infância. Entre outros, encontramos o texto “Jardim de Infância n. ${ }^{1}$ de Portalegre” (CARRILHO et al., 1987) que relata uma experiência de cooperação com pais daquele Jardim de Infância potenciando a relação Escola/Família.

Diagnosticado o problema da transição entre o meio familiar e o Jardim de Infância, as educadoras promoveram uma ação de integração onde os pais participavam ativamente "tentando assim facilitar o ingresso neste mundo desconhecido para a criança" 
Assim, foram feitos encontros (pais, criança, educadora) com a duração aproximadamente de trinta minutos, proporcionando o conhecimento da sala e um contacto individual com a educadora antes do início das actividades lectivas. Falou-se no porquê das salas divididas em áreas (cantinhos), explicou-se a função do Jardim de Infância, que tem como factores predominantes a sociabilização da criança e o desenvolvimento global de potencialidades. ( CARRILHO et al., 1987, p. 34)

Esta ação assumiu como propósito o esclarecimento sobre o papel social e educativo do jardim de infância, junto dos pais. Mostrar aos pais a importância do "ofício de ser criança" e que esse "ofício" não passava necessariamente pela aprendizagem escolarizada, antes pela aprendizagem através do brincar, como propunham os renovados modelos pedagógicos naquela altura. Esta atividade repercutiu-se nas crianças e nos pais. Na verdade, em testemunho publicado na revista em análise sobre a iniciativa pode ler-se:

Penso que a ideia foi óptima. Só soubemos exactamente de que se tratava quando chegámos à sala. Vimos então o que era a surpresa para as crianças. Cada um tinha que fazer o que lhe viesse à cabeça. Uns pais optaram pelo desenho e cada um escolheu aquilo para que tinha mais habilidade. Nós - eu e outro pai - escolhemos aquele cantinho (da cozinha), os outros já estavam ocupados e como não tenho grande habilidade para desenho optei pela cozinha. Tivemos que optar por aquilo que havia e fazer o nosso "servicinho": guardanapos, toalhas, trabalhos com plasticina, trabalhos com o resto dos trapos que havia, trabalhos com esferovite... a garrafa do sumo teve de ser também improvisada (...) (CARRILHO et al., 1987, p. 36)

O envolvimento dos pais, o contacto com as salas de atividades e o trabalho criativo com as crianças constituíram um fator de integração de grande importância no início daquele ano letivo. Os pais, de acordo com o seu testemunho, passaram a olhar para as atividades desenvolvidas pelos educadores de infância com outros olhos, passaram a olhar para estes profissionais como alguém que educa as crianças com método e intencionalidade.

No decorrer da análise evidenciaram-se também experiências pedagógicas um pouco mais dirigidas aos estudantes em formação. É o caso de um texto dirigido aos estudantes onde se descrevia o processo de organização de uma "biblioteca" no Jardim de Infância. Sobre este assunto Marchão (1991) escreve sobre a importância dos livros de 
qualidade, naquele contexto educativo, e da forma como se devem explorar. Afirma que "o contacto com o livro deve nascer desde muito cedo (no seio familiar, na creche), privilegiando-se nesta fase livros de cartão grosso, com imagens simples e sugestivas e sem/ou com texto escrito, muito simples e claro para as crianças" (MARCHÃO, 1991, p. 88).

Ao educador de infância deve caber a missão de "desenvolver o gosto pelo livro" colocando-os à disposição das crianças das mais variadas formas colocando-o:

... à disposição das crianças; visitando locais de venda de livros; visitando bibliotecas; sugerindo-lhe e fazendo com que a criança defina regras de contacto com os livros; lendo histórias (mas não descuidando as poesias "sem livro"); lendo lenga-lengas (mas não descuidando lenga-lengas sem livro); lendo informação de carácter vário; explorando com as crianças imagens de livros; explorando com as crianças imagens de cartazes, postais...; comentando com as crianças as informações dos livros; elaborando registos de conversas e/ou de expressão gráfica das crianças; construindo livros com as crianças: de imagens (construídas pelas crianças, ilustrações ou colagens...), de imagens e texto escrito (ilustração e texto oral da criança); incentivando a que as crianças tragam livros de casa; construindo o jornal da sala; elaborando histórias... (MARCHÃO, 1991, p. 89)

A emergência do gosto pela leitura e pelo livro pode, e deve ser estimulado logo nos primeiros anos de vida da criança. Cabe à família e ao profissional de educação de infância alimentar esse gosto sem, contudo, direcionar a aprendizagem no sentido escolarizante, porque esse não deve ser o objetivo deste contexto educativo.

Encontramos outros relatos de experiências pedagógicas realizados no âmbito do Jardim de Infância no âmbito de diversos saberes: em Ciências (da natureza), “À descoberta de objectos e materiais condutores da electricidade por crianças de 4/5 anos" (SÁ, 1996, p. 65); em História, "História da História. Marvão no dia Mundial da Criança” (MOGARRO et al., 1999, p. 119); a participação no projeto das Escolas Rurais do Nordeste Alentejano, encontrando-se textos associados ao Jardim de Infância nomeadamente: um percurso rumo a uma Oficina de Marionetas em Santo Aleixo (SILVA et. Al, 2002, p. 62) 
ou, ainda, relatos de educadoras em "Formar para agir em continuidade: uma experiência de formação na ESE de Portalegre" (GARCIA et al., 2002, p. 69).

Mais recentemente investiu-se nas problemáticas relacionadas com a educação para a cidadania. Em particular, a dimensão explorada prende-se com as questões da igualdade de oportunidades entre meninos e meninas/homens e mulheres através de experiências de aprendizagem diversas que acontecem nos contextos educativos fruto da ação reflexiva na instituição de formação É esta nova linha de trabalho que se encontra evidenciada a partir do número 36, publicado em 2015, onde surgem vários trabalhos relacionados com as questões da "educação, cidadania e igualdade de oportunidades: olhares sobre a educação de infância" (MARCHÃO, HENRIQUES, 2015, p. 72) ou da autoria de Cardona (2015, p. 63) intitulado "Trabalhar as questões de género numa perspetiva de educação para a cidadania no Jardim de Infância e na escola”. Todos estes exemplos partem de ideias ou experiências desenvolvidas com os estudantes e aplicados no contexto educativo.

\section{Considerações finais}

A Revolução de 25 de Abril de 1974 impulsionou a constituição de uma rede de jardins de infância por todo o país. A evolução da educação de infância deveu-se em grande parte a uma ação estatal significativa através, em particular, da publicação de dois diplomas estruturantes: a Lei de Bases do Sistema Educativo (1986) e a Lei Quadro para a Educação Pré-Escolar (1997). A preocupação com a educação das crianças mais novas traduziu-se em ganhos consideráveis para o desenvolvimento da população portuguesa. Para esta dinâmica contribuíram as instituições formadoras de professores e educadores, como a Escola Superior de Educação e Ciências Sociais do Instituto Politécnico de Portalegre, que formou centenas de profissionais desde a década de 80 até ao presente.

Ao longo da análise realizada evidenciaram-se algumas realidades que agora sintetizamos: por um lado, percebemos que, apesar da importância crescente da educação de infância na vida dos portugueses e no contexto formativo destes profissionais, a dimensão da produção pedagógica revelou-se, do ponto de vista quantitativo, no caso estudado, muito débil e exígua. Por outro lado, no que respeita às 
temáticas abordadas reconhece-se a existência de um enorme interesse de um conjunto de pessoas muito definido - principalmente educadoras ou professores ligados a contexto de práticas pedagógicas - pelas problemáticas relacionadas com a educação de infância que publicaram os seus trabalhos na revista. É o caso de Marchão (1995), inspirada em autores diversos, que afirma os princípios de uma educação onde a criança deve constituir-se como o centro dos interesses pedagógicos numa perspetiva dinamizadora das suas capacidades na relação com o mundo envolvente e onde o "brincar" é crucial à sua aprendizagem. Ou, por fim, realçamos o conjunto significativo de experiências pedagógicas diversas que vários docentes da Escola Superior de Educação de Portalegre foram realizando, no contexto de Prática Supervisionada, colocando os seus estudantes, futuras educadoras de infância, em contacto com as crianças, desafiando-as a aprender a brincar ou potenciando projetos pedagógicos no meio de inserção dos jardins de infância. Verificamos, também, que a produção do pensamento pedagógico daqueles que publicaram na Aprender estava muito relacionado com a dimensão prática da futura profissional.

Em suma, a produção do pensamento pedagógico sobre a educação de infância constitui uma pequena parte de um amplo movimento desenvolvido pela ação do Estado Português, num contexto marcado pelo desenvolvimento das ideias de liberdade, justiça social, solidariedade ou democracia, por todo o território nacional, onde as ESE assumiram um papel central na profusão destes ideais através da formação de professores e educadores, em particular no que respeita aos princípios pedagógicos a desenvolver em contexto de jardim de infância e na formação dos futuros educadores. 


\section{Referências}

AFONSO, Natércio. Ese: que modelo para a formação inicial?. Aprender. n. 1, p. 9-11, 1987.

ALMEIDA, Ana Maria. Para uma sociologia da infância: jogos de olhares, pistas para a investigação. Lisboa: ICS, 2009.

BAIRRÃO, João; VASCONCELOS, Teresa. A educação pré-escolar em Portugal: contributos para uma perspetiva histórica. Inovação: revista do Instituto de Inovação Educacional, v. 10, n. 1, p. 7-19, 1997.

CANÁRIO, Rui. Editorial. Aprender. n. 1, p. 1-2, 1987.

CARDONA, Maria João. Para a história da educação de infância em Portugal: o discurso oficial (1834.1990). Porto: Porto Editora, 1997.

CARDONA, Maria João. Trabalhar as questões de género numa perspetiva de educação para a cidadania no Jardim de Infância e na escola. Aprender. n. 36, p.63, 2015.

CARRILHO, Maria Rosa Louro et. al. Jardim de Infância. Aprender, Portalegre, n.2, 1987.

CASTANHEIRA, Luís. Para a história da educação de infância em Portugal: o caso de Bragança (1934-1986). 2011. Dissertação (Doutoramento em História da Educação) Universidade de Lisboa, Lisboa, 2011.

CATANI, Denice. A imprensa periódica pedagógica e a história dos estudos educacionais no Brasil. In: HERNANDEZ DIAZ, José Maria (Coord.). La prensa pedagógica y patrimonio histórico educativo: contribuciones desde la Europa mediterránea e Iberoamérica. Salamanca: Ediciones Universidad Salamanca, 2013. p. 115 -122.

ESCOLA SUPERIOR DE EDUCAÇÃO DE PORTALEGRE . Escola Superior de Educação de Portalegre: Balanço de Cinco anos de actividade 1985-1990, Portalegre, 1990.

FERNANDES, Rogério. Educação e ensino popular na Madeira (Sec. XVIII - 1840). In: FELGUEIRA, Margarida Louro; MENEZES, Maria Cristina (Orgs.). Rogério Fernandes: questionar a sociedade, interrogar a história (re)pensar a educação. Porto: Edições Afrontamento, 2006. p. 125-182.

FOUCAULT, Michel. Estratégia, poder-saber. Rio de Janeiro: Forense Universitária, 2006.

GARCIA, Ana Maria et. al.. Formar para agir em continuidade. Uma experiência de formação na Ese de Portalegre. Aprender. n. 26, p.69-73, 2002.

GOMES, Joaquim. A Educação infantil em Portugal. 2. ed. Coimbra: INIC/CPUC, 1986.

HENRIQUES, Helder; MARCHÃO, Amélia. A educação de infância portuguesa e o modelo de Reggio Emilia: a promoção da igualdade de género a partir de práticas de investigação. In: DÍAZ, H. Influencias italianas en la educación española e iberoamericana. Salamanca: FahrenHouse Ediciones, 2014. p. 527-540. 
HENRIQUES, Hélder; MARCHÃO, Amélia, MOURATO, Joaquim. A Democracia e o Ensino Superior Politécnico Português. O caso do Instituto Politécnico de Portalegre (década de 80 do séc. XX). Espacio, Tiempo y Educación, V. 2 jul./Dic., 2015.

HENRIQUES. Helder; VILHENA, Carla. A preservação da infância: análise de discursos sobre a criança em perigo moral (Portugal, 1910-1916). Educ. rev.[online], v. 31, n. 2, p. 61$81,2015$.

HERNANDEZ DIAZ, José Maria (Org.). Prensa pedagógica y patrimonio histórico educativo. Salamanca: Ediciones Universidad de Salamanca, 2013.

HERNANDEZ DIAZ, José Maria (Coord.). La prensade los escolares y estudiantes: su contribución al património histórico, 2015.

MAGALHÃES, Justino. Para uma história da educação de infância em Portugal. Saber (e) Educar, n. 2, p. 21-26, 1997.

MARCHÃO, Amélia; HENRIQUES, Helder. Educação, cidadania e igualdade de oportunidades: olhares sobre a educação de infância. Aprender. n. 36, p. 72-85, 2015.

MARCHÃO, Amélia. Como organizar a "zona da biblioteca" no Jardim de Infância.

Aprender. n. 13, p. 88-90, 1991.

MARCHÃO, Amélia. As escolas superiores de educação e a formação de educadores de infância. Aprender. n. 19, p. 97-99, 1995.

MARCHÃO, Amélia. Formação de educadores de infância para a creche uma aposta de futuro para as instituições de formação. Aprender. n. 21, p. 51-53, 1998.

MARCHÃO, Amélia. Da formação de educadores e professores aos processos de construção e gestão do currículo nas $1^{\mathrm{a}} \mathrm{s}$ etapas da educação básica (Educação Préescolar, $1^{\circ}$ ciclo). Aprender, p. 33-40, 2002.

MARCHÃO, Amélia. No jardim de infância e na escola do $10^{\circ}$ ciclo do ensino básico: gerir o currículo e criar oportunidades para construir o pensamento crítico. Lisboa: Edições Colibri, 2012.

MOGARRO, Maria João et al. História das história. Aprender, n. 23. p.119 -131, 1999.

MONGE, Maria Graciete. Educação Pré-escolar $/ 1^{\circ}$ ciclo do Ensino Básico - uma perspetiva de continuidade educativa. Aprender. n. 26, p. 17-26, 2002.

NÓVOA, António. História da educação. Universidade de Lisboa: Faculdade de Psicologia e de Ciências da Educação, 1994.

OCEPE. Orientações curriculares para a Educação Pré-escolar. Lisboa: Ministério da Educação, 1997. 
OCEPE. Orientações curriculares para a Educação Pré-escolar. Lisboa: Ministério da Educação, 2016. Disponível em: <http://www.dge.mec.pt/ocepe/ >. Acesso em: 16 jun. 2017.

SÁ, Joaquim. A descoberta de objectos e materiais condutores da electricidade por crianças de 4/5 anos. Aprender, n. 20, p. 65-70, 1996.

SERRAZINA, Maria de Lurdes. Algumas considerações sobre os currículos de matemática nos ensinos pré-escolar e primário. Aprender, n. 6, p. 23-27, 1988.

SILVA, Ana Isabel et al. Um percurso rumo a uma Oficina de Marionetas em Santo Aleixo. Aprender. n. 26, p. 62-65, 2002.

SILVA, Maria Isabel Lopes da. Ser professor do $1^{\circ}$ ano: que continuidade com a Educação Pré-escolar?. Aprender. n. 26, p.17-26, 2002.

VASCONCELOS, Teresa. Das casas de asilo ao projecto de cidadania: políticas de expansão da educação de infância em Portugal. Porto: Edições Asa, 2005.

Universidade do Estado de Santa Catarina - UDESC

Programa de Pós-Graduação em Educação - PPGE Revista Linhas

Volume 18 - Número 38 - Ano 2017 revistalinhas@gmail.com 